Retraction note: Edge-oriented spatial interpolation for error concealment of consecutive blocks. JOURNAL OF COMPUTER SCIENCE AND TECHNOLOGY 35(6): 1490 Nov. 2020. DOI 10.1007/s11390-012-9999-7

\title{
Retraction Note: Edge-Oriented Spatial Interpolation for Error Concealment of Consecutive Blocks
}

Published Online: October 12, 2012.

Retraction: Wei Fu and Guang-Zhong Xing. Edge-Oriented Spatial Interpolation for Error Concealment of Consecutive Blocks. Journal of Computer Science and Technology 2007, 22(3): 494-inside back cover. DOI: 10.1007/s11390-007-9044-4.

This article was published twice in Journal of Electronics (China), 2007, 24(2): 214-217 under the title of "A Modified Edge-Oriented Spatial Interpolation Algorithm for Consecutive Blocks Error Concealment", and in Journal of Computer Science and Technology, 2007, 22(3): 494-497 under the title of "Edge-Oriented Spatial Interpolation for Error Concealment of Consecutive Blocks". Due to disputes about where the article first appeared this article has been retracted. 